\title{
Utilizing the assassin bug, Pristhesancus plagipennis (Hemiptera: Reduviidae), as a biological control agent within an integrated pest management programme for Helicoverpa spp. (Lepidoptera: Noctuidae) and Creontiades spp. (Hemiptera: Miridae) in cotton
}

\author{
P.R. Grundy* \\ Plant Science, Department of Primary Industries and Fisheries, Locked \\ Mail Bag 1, Biloela, Queensland 4715, Australia
}

\begin{abstract}
Helicoverpa spp. and mirids, Creontiades spp., have been difficult to control biologically in cotton due to their unpredictable temporal abundance combined with a cropping environment often made hostile by frequent usage of broad spectrum insecticides. To address this problem, a range of new generation insecticides registered for use in cotton were tested for compatibility with the assassin bug, Pristhesancus plagipennis (Walker), a potential biological control agent for Helicoverpa spp. and Creontiades spp. Indoxacarb, pyriproxifen, buprofezin, spinosad and fipronil were found to be of low to moderate toxicity on P. plagipennis whilst emamectin benzoate, abamectin, diafenthiuron, imidacloprid and omethaote were moderate to highly toxic. Inundative releases of $P$. plagipennis integrated with insecticides identified as being of low toxicity were then tested and compared with treatments of $P$. plagipennis and the compatible insecticides used alone, conventionally sprayed usage practice and an untreated control during two field experiments in cotton. The biological control provided by $P$. plagipennis nymphs when combined with compatible insecticides provided significant $(P<0.001)$ reductions in Helicoverpa and Creontiades spp. on cotton and provided equivalent yields to conventionally sprayed cotton with half of the synthetic insecticide input. Despite this, the utilization of $P$. plagipennis in cotton as part of an integrated pest management programme remains unlikely due to high inundative release costs relative to other control technologies such as insecticides and transgenic $(\mathrm{Bt})$ cotton varieties.
\end{abstract}

Keywords: mirids, predators, inundative, mass release 


\section{Introduction}

Arthropod predators and parasitoids are considered to be important pest mortality agents in Australian cotton production systems, although they are rarely capable of controlling Helicoverpa spp. (Lepidoptera: Noctuidae) unassisted (Fitt, 2000; Mensah, 2002). In recent years, there has been a shift towards integrated pest management strategies that include the use of more selective spectrum insecticides (Holloway \& Forrester, 1998), Helicoverpa spp. biopesticides (Mensah et al., 2005) and sacrificial trap crops grown to divert pest species from cropping areas (Sequeira, 2001; Grundy et al., 2004); however, predator and parasitoid utilization in Australian cotton remains predominantly passive.

A conservational approach, through judicious insecticide selection, has been shown to increase the diversity and abundance of beneficial arthropods in cotton (Mansfield et al., 2006) and generally improve gross margins (Hoque et al., 2000). Bollgard $\AA$ (Bt) varieties have been broadly adopted by the Australian industry during the last decade with an expectation that $\mathrm{Bt}$ varieties would provide a platform for vastly reducing pesticide usage from the conventional average of 12 applications per season (Doyle et al., 2002) and consequently increase the robustness of natural enemy complexes (Fitt, 2000; Wilson et al., 2006). However, despite the reduction in spraying for Helicoverpa spp. and associated expectations for improved predation and para-

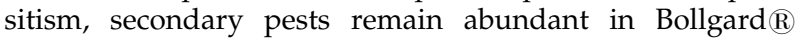
cotton crops and often require insecticide intervention (Wilson et al., 2006).

Although the conservation approach to biological control has provided a way for the Australian cotton industry to reduce insecticide dependence, agro-ecosystems are inherently changing environments and the abundance of natural enemies fluctuate due to many biotic and abiotic factors that are poorly understood (Stanley, 1997). The unpredictability of natural predators and parasitoids remains a key factor limiting their greater exploitation in Australian cotton pest management programmes (Johnson et al., 2000).

Although augmentation by mass release is one method that could be used to increase the reliability and effectiveness of predators and parasitoids within cropping systems (New, 2002), the potential of generalist predators, particularly predatory bugs, has been largely ignored in cotton production systems (King \& Powell, 1992). However, in a monoculture environment where the main pests, Helicoverpa spp. and Creontiades spp. (Hemiptera: Miridae), are characterized by migratory behaviour and a multi-voltine lifecycle (Zalucki et al., 1986; Miles, 1995), generalist predators may have a survival advantage as their population dynamics are not solely dependent on any one pest species (Murdoch et al., 1985; Nyffeler et al., 1992).

The assassin bug, Pristhesancus plagipennis (Walker) (Hemiptera: Reduviidae), is a generalist predator of various insects in both orchard and field crops (Pyke \& Brown, 1996; Smith et al., 1997). Several studies have suggested that $P$. plagipennis may be suited for augmentation against Helicoverpa spp. and Creontiades spp. with inundative releases resulting in reduced populations of these pests in cotton (Grundy \& Maelzer, 2000, 2002; Grundy, 2004). Densities of one $P$. plagipennis nymph per metre row $\left(10,000\right.$ nymphs ha $\left.^{-1}\right)$ were sufficient to reduce Helicoverpa spp. larvae densities on cotton (Grundy \& Maelzer, 2002; Grundy, 2004). However, it was evident during these experiments that release rates of one $P$. plagipennis nymph per metre row were insufficient to control Helicoverpa spp. during peak infestation events that can occur on cotton during some seasons (Fitt, 2000). The pre-emptive release of higher $P$. plagipennis numbers that might counter peak population events was shown to be an unsuccessful strategy with high losses of nymphs occurring from the plots during periods of low pest abundance due possibly to starvation and/or cannibalism (Grundy \& Maelzer, 2000, 2002). A more reliable method may be one that utilizes the biological control afforded by $P$. plagipennis during periods of low to moderate pest abundance and allows for the use of compatible insecticides during peak pest invasion events.

Earlier insecticide compatibility studies suggested that $P$. plagipennis were tolerant of some organochlorine and carbamate insecticides (Grundy et al., 2000a). However, these insecticides are generally considered toxic to a range of other beneficial insects found in Australian cotton fields for which disruption can give rise to secondary pest problems (Wilson et al., 1998) and are, therefore, unsuitable for use within integrated pest management programmes that seeks to emphasize the conservation of natural enemies for biological control. Several selective new generation insecticides (e.g. spinosans, mectins, nicotinoids) have since entered the Australian marketplace, some of which have been identified as being less disruptive to a range of beneficial insects that occur in cotton (Deutscher et al., 2004) and, if compatible with $P$. plagipennis, may be suited for integration.

The objective of the present study was to identify the compatibility of a range of new generation insecticides with $P$. plagipennis nymphs and to then test an integrated field release strategy where $P$. plagipennis and compatible insecticides were combined and compared with unsprayed and conventionally sprayed cotton treatments.

\section{Materials and methods}

The $P$. plagipennis nymphs used in the experiments were progeny reared from adult bugs originally collected from the Coffs Harbour $\left(23^{\circ} 16^{\prime} \mathrm{S}, 150^{\circ} 21^{\prime} \mathrm{E}\right)$ and Rockhampton $\left(29^{\circ} 59^{\prime} \mathrm{E}, 153^{\circ} 08^{\prime} \mathrm{S}\right)$ regions of New South Wales and Queensland, respectively. Pristhesancus plagipennis used in each study were reared on a diet of Tenebrio molitor (Linnaeus) in a constant climate laboratory at $26 \pm 1^{\circ} \mathrm{C}$ and $55-75 \% \mathrm{RH}$, with a $15: 9 \mathrm{~L}: \mathrm{D}$ photoperiod supplied by cool white 36 watt fluorescent tubes (Grundy et al., 2000b).

\section{Insecticide compatibility}

Four-day-old first instar P. plagipennis were used in each experiment, as earlier studies indicated that this stage was the most sensitive and, therefore, provided a 'worst case' test result (Grundy et al., 2000a). Pesticides that are found to be non-toxic using the assumptions of a 'worst case' test generally require no further testing on other stages (Hassan et al., 1994).

The active ingredient, formulation and manufacturer for each insecticide treatment are listed (table 1). The commercial formulation of each insecticide was tested at its maximum registered rate for the control of insect pests on cotton within Australia as well as at three dilutions (75, 50 and $25 \%$ of the recommended rate), as the application of insecticides at below label rates for the improved 
Table 1. Active ingredient (AI), formulation and recommended application rates of insecticides compared for their activity against P plagipennis.

\begin{tabular}{|c|c|c|c|c|}
\hline Active ingredient & $\begin{array}{l}\mathrm{g} \mathrm{AIl}^{-1} \text { and } \\
\text { formulation }\end{array}$ & Manufacturer & \multicolumn{2}{|c|}{ Application rate } \\
\hline Bacillus thuringiensis & Biological & Valent & 20 & 2 \\
\hline Buprofezin & $200 \mathrm{gl}^{-1} \mathrm{EC}$ & Syngenta & 10 & 1 \\
\hline Pyriproxifen & $500 \mathrm{gl}^{-1} \mathrm{EC}$ & Sumitomo & 5 & 0.5 \\
\hline Indoxacarb & $200 \mathrm{gl}^{-1} \mathrm{SC}$ & Du Pont & 8.5 & 0.85 \\
\hline Emamectin benzoate & $17 \mathrm{gl}^{-1} \mathrm{EC}$ & Syngenta & 5.5 & 0.55 \\
\hline Abamectin & $18 \mathrm{gl}^{-1} \mathrm{EC}$ & Syngenta & 6 & 0.6 \\
\hline Diafenthiuron & $500 \mathrm{gl}^{-1} \mathrm{SC}$ & Syngenta & 6 & 0.6 \\
\hline Imidacloprid & $200 \mathrm{gl}^{-1} \mathrm{SC}$ & Bayer Crop Science & 2.5 & 0.25 \\
\hline Omethoate & $800 \mathrm{gl}^{-1} \mathrm{SL}$ & Bayer Crop Science & 1.4 & 0.14 \\
\hline
\end{tabular}

EC, emulsifiable concentrate; SC, suspension concentrate; SL, soluble liquid.

conservation of natural enemies has become commonplace within the Australian cotton industry (Deutscher et al., 2004).

For the laboratory tests, disposable $200 \mathrm{~mm}$ diameter Petri dishes were used as a standardized application target. The Petri dishes were modified by punching four $30 \mathrm{~mm}$ diameter holes into the lid of each container and gluing a piece of muslin gauze over the opening for ventilation. A Potter Precision spray tower was then used to apply $2 \mathrm{ml}$ aliquots of insecticide to the upper and lower inner surface of each Petri dish as described by Holland \& Chapman (1995) and Herron et al. (1998).

Agral $\AA$ non-ionic wetter (nonyl phenol ethylene oxide condensate) (Crop Care, Australia) was added at the rate of $0.1 \mathrm{mll}^{-1}$ to each insecticide suspension before application because wetting agents are commonly mixed with pesticides to enhance spray coverage in Australia. Agral was also mixed with distilled water at the same rate and used as a control treatment.

The experiment was conducted on 11 August 2002. Three replicates of 30 nymphs were topically treated on the Petri dish plates with one of the four concentrations of each product. Before being treated, the nymphs were temporarily immobilized with carbon dioxide $\left(\mathrm{CO}_{2}\right)$ to allow easy handling and to slow the nymphs from escaping the open Petri dishes during application. After treatment, the Petri dishes containing the sprayed nymphs were placed in a constant climate laboratory under conditions used for rearing for $24 \mathrm{~h}$. The nymphs were then transferred to clean Petri dishes and provided with T. molitor prey larvae, and those that successfully moulted to the second instar were recorded as having survived the treatment.

A second experiment was conducted to examine the tolerance of each nymphal instar to emamectin benzoate, spinosad, fipronil and indoxacarb. The full recommended rate of each product was applied to three replicates (30 nymphs per replicate) of each nymph stage using the same methods of application and assessment outlined for the first experiment.

\section{Field studies}

Two experiments were conducted within a 2.5-ha irrigated field planted to cotton (cv. Sicot 71) during the summer of 2002/03 and 2003/04 near the township of Biloela, central Queensland $\left(24^{\circ} 22^{\prime} \mathrm{S}, 150^{\circ} 06^{\prime} \mathrm{E}\right)$. In each experiment, treatment plots with dimensions $30 \mathrm{~m} \times 10 \mathrm{~m}$ and $1 \mathrm{~m}$ row spacing were arranged in a randomized block design with five replicates of each treatment. The plots were separated by $6 \mathrm{~m}$ buffers, which consist of $2 \mathrm{~m}$ of bare earth adjacent to a $2 \mathrm{~m}$ strip of cotton on all sides.

Five treatments were compared in each experiment.

1. Third instar $P$. plagipennis released at one nymph per $m$ row $(10,000$ nymphs per hectare) with no other control inputs.

2. The same $P$. plagipennis release treatment combined with selected compatible soft insecticides.

3. A soft insecticide sprayed treatment to which the same compatible insecticides were applied at the same time as those applied with the soft insecticide and $P$. plagipennis treatment plots.

4. A conventionally sprayed treatment, which was managed with insecticides that would be generally applied by growers using a conservational approach (avoidance of broad spectrum insecticides).

5. A P. plagipennis nymph and insecticide free control.

Pristhesancus plagipennis nymphs were released in each experiment within a week of the first flowers appearing on the crop on 15 and 20 December 2002 and 2003, respectively. Nymphs for each treatment were released singularly onto the terminal shoots of the crop foliage using a camel-hair brush late in the afternoon after $1700 \mathrm{~h}$ during each experiment.

The sprayed treatments were managed with insecticides chosen in accordance to the Insecticide Resistance Management Strategy set by the Australian cotton industry for each season (Schulze \& Tomkins, 2002; Johnson \& Farrell, 2003). Application decisions were based on commercially accepted density thresholds for Helicoverpa spp. and Creontiades spp. as well as crop damage models for bud and fruit retention (Schulze \& Tomkins, 2002; Johnson \& Farrell, 2003). Insecticide applications on the sprayed plots were made at daybreak whilst wind was minimal to avoid insecticide drift into adjacent plots. A record of the insecticides applied to the sprayed treatment and the soft insecticide treatments is given in table 2. No pesticides were used on the crop area 
Table 2. The insecticides applied to the conventionally sprayed (CS), soft insecticide only (SI) and soft insecticide with Pristhesancus plagipennis (SI \& Pp) treatments during the 2002/03 and 2003/04 experiments.

\begin{tabular}{|c|c|c|c|c|}
\hline Pest & $\begin{array}{c}\text { Active } \\
\text { ingredient }\end{array}$ & Rate & $\begin{array}{l}\text { Treatments } \\
\text { sprayed }\end{array}$ & $\begin{array}{c}\text { Application } \\
\text { date }\end{array}$ \\
\hline \multicolumn{5}{|l|}{ 2002/03 Experiment } \\
\hline Helicoverpa & NPV & $500 \mathrm{ml} \mathrm{ha}^{-1}$ & CS, SI, SI \& Pp & 13 Dec 2002 \\
\hline Helicoverpa & Spinosad & $200 \mathrm{ml} \mathrm{ha}^{-1}$ & CS & 20 Dec 2002 \\
\hline Helicoverpa and mirids & Fipronil/NPV & $\begin{array}{l}40 \mathrm{mlha}^{-1} \\
\quad \& 250 \mathrm{mlha}^{-1}\end{array}$ & CS, SI and SI \& Pp & 9 Jan 2003 \\
\hline Helicoverpa & Indoxacarb & $750 \mathrm{ml} \mathrm{ha}^{-1}$ & CS, SI, SI \& Pp & 20 Jan 2003 \\
\hline \multicolumn{5}{|l|}{ 2003/04 Experiment } \\
\hline Helicoverpa & NPV & $500 \mathrm{ml} \mathrm{ha}^{-1}$ & CS, SI, SI \& Pp & 30 Dec 2003 \\
\hline Helicoverpa & NPV & $250 \mathrm{ml} \mathrm{ha}^{-1}$ & SI, SI \& Pp & 5 Jan 2004 \\
\hline Helicoverpa & Spinosad & $200 \mathrm{ml} \mathrm{ha}^{-1}$ & CS & 5 Jan 2004 \\
\hline
\end{tabular}

NPV, nucleo polyhedrovirus.

except for those sprayed treatment plots. In each experiment, pre-release pest insect counts were made prior to predator release and then every 3-7 days until the end of the experiment. The data were expressed as numbers of insects per metre row for each treatment.

Visual counts of Helicoverpa spp. eggs and larvae on the cotton plants were made on four randomly selected $1 \mathrm{~m}$ row lengths of cotton plants in each treatment replicate. The growing points and squares of the upper two-thirds of the plant canopy were searched for eggs and small larvae because these instars are frequently found in those plant regions (Farrer \& Bradley, 1985). Flowers and bolls throughout the plant canopy were also inspected for larger larvae. Larvae were recorded as small $(2-10 \mathrm{~mm})$, medium $(11-20 \mathrm{~mm})$ and large $(>20 \mathrm{~mm})$. Numbers of $P$. plagipennis nymphs were recorded at the same time.

A beat sheet sampling method was used to assess the presence of Creontiades spp. and other insects. The sheet used was $1.5 \mathrm{~m}$ wide by $2 \mathrm{~m}$ long and made from yellow canvas. A $25 \mathrm{~mm}$ diameter piece of timber dowel $(1.5 \mathrm{~m}$ long) was fixed to each end of the sheet to prevent the ends lifting in the wind. Samples were taken by placing the sheet behind the cotton plants to be sampled, along the inter-row and up over the adjacent row of cotton to create a 'wall' to catch flying insects. A 1-m long stick was used to shake $1 \mathrm{~m}$ of row onto the sheet for assessment. The cotton bushes were shaken several times from the base of the plants to the top. Dislodged insects were aspirated off the sheets with a domestic-styled hand-held vacuum appliance (Breville BHV2) and returned to the laboratory for thorough assessment. Beat sheet samples were made on four randomly selected $1 \mathrm{~m}$ row lengths of cotton plants in each treatment replicate.

Each crop was grown through to harvest. Heavy rain due to a hurricane depression delayed the harvest of the 2002/03 crop and resulted in significant yield losses due to boll rot and weather damage. The cotton was picked from the six central rows of each treatment replicate with an experimental two-row picker. The 2002/03 crop was picked on 10 April 2003 and the 2003/04 crop was picked on 11 March 2004.

The cotton picked from each plot was weighed and a sub-sample taken for ginning to determine the relative proportions of lint and seed. The yield from each plot was divided by the sub-sample gin turnouts for the proportion of lint and seed from which yield in bales of cotton lint $(227 \mathrm{~kg}$ per bale) per hectare could be calculated.

Environmental conditions were recorded during the experiment with a Mark 4 weather station (Environdata, Warwick, Queensland).

\section{Analysis of data}

The nymph mortality data from the insecticide compatibility experiments was corrected for control mortality using Abbott's formula (Abbott, 1925) and was analysed using ANOVA in GenStat (Payne et al., 1989). Least significant differences (LSDs) were calculated to determine treatment differences at $P<0.05$. An angular transformation was considered for the mortality data but deemed unnecessary.

Count data for Helicoverpa spp., Creontiades spp. and other insects at each sampling date were analysed using a repeated measurements analysis using the method of residual maximum likelihood (REML) with ante dependence covariate structure of order 1 using GenStat. This model was used to assess treatment effects for each experiment. Wald tests were used to assess overall treatment differences. Differences between treatments were determined by comparing predicted means using the standard error of differences.

\section{Results \\ Insecticide compatibility}

Significant differences were found between insecticides $(P<0.05$, LSD 4.55$)$, dose rates $(P<0.05$, LSD 2.74$)$ and the interaction between dose and insecticides tested $(P<0.05$, LSD 9.11). Pyriproxifen, buprofezin, Bacillus thuringiensis and nucleopolyhedrovirus were non-toxic to $P$. plagipennis nymphs whilst indoxacarb was of very low toxicity. Spinosad, fiprinol, emamectin benzoate and abamectin were of low to moderately high toxicity, respectively, with each product having a significant dose response $(P<0.05)$ with reduced application rates. Diafenthiuron, imidacloprid and omethoate were highly toxic to $P$. plagipennis nymphs even when applied at reduced rates (table 3). For intermediate 
Table 3. Percentage mortality $( \pm \mathrm{SE})$ of first instar Pristhesancus plagipennis treated with various insecticides in laboratory bioassays.

\begin{tabular}{lcccc}
\hline Product & \multicolumn{4}{c}{ Percentage of recommended field rate tested } \\
\cline { 2 - 5 } & 100 & 75 & 50 & 25 \\
\hline Bacillus thuringiensis & 0 & 0 & 0 & 0 \\
Nucleopolyhedrovirus & 0 & 0 & 0 & 0 \\
Buprofezin & 0 & 0 & 0 & 0 \\
Pyriproxifen & $2.2 \pm 0.1$ & 0 & 0 & 0 \\
Indoxacarb & $7 \pm 2.8$ & $2 \pm 0.1$ & 0 & $7 \pm 3.4$ \\
Spinosad & $27 \pm 1.9$ & $11 \pm 0.1$ & $12 \pm 1.93$ & $14 \pm 0.1$ \\
Fipronil & $43 \pm 2.8$ & $25 \pm 3.0$ & $18 \pm 1.1$ & $16 \pm 2.3$ \\
Emamectin benzoate & $69 \pm 8.4$ & $47 \pm 2.8$ & $42 \pm 8.1$ & $41 \pm 8.5$ \\
Abamectin & $84 \pm 1.1$ & $61 \pm 2.0$ & $51 \pm 1.9$ & $84 \pm 1.1$ \\
Diafenthiuron & 100 & 100 & $91 \pm 2.8$ & $94 \pm 1.0$ \\
Imidacloprid & 100 & 100 & $96 \pm 0.9$ & 100 \\
Omethoate & 100 & 100 & 100 & \\
\hline
\end{tabular}

Table 4. Percentage mortality $( \pm \mathrm{SE})$ of each Pristhesancus plagipennis instar treated with various insecticides at the full recommended rate in laboratory bioassays.

\begin{tabular}{lrrrrr}
\hline Product & \multicolumn{5}{c}{ Percentage mortality of each P. plagipennis instar } \\
\cline { 2 - 6 } & \multicolumn{1}{c}{ I } & II & III & IV & V \\
\hline Indoxacarb & $6 \pm 2.7$ & $4 \pm 2.7$ & 0 & 0 & 0 \\
Spinosad & $28 \pm 2.9$ & $11 \pm 2.2$ & $4 \pm 2.2$ & 0 & 0 \\
Fipronil & $39 \pm 5.5$ & $29 \pm 2.2$ & $18 \pm 4.4$ & $9 \pm 2.2$ & $4 \pm 2.7$ \\
Emamectin benzoate & $65 \pm 9.4$ & $33 \pm 3.8$ & $11 \pm 2.2$ & $8 \pm 1.9$ & $4 \pm 2.2$ \\
\hline
\end{tabular}

toxicity products (table 3) significant differences were found between insecticides $(P<0.05$, LSD 3.54) and the different $P$. plagipennis instars $(P<0.001, \mathrm{LSD} 3.54)$ and the interaction between dose and insecticides tested $(P<0.001$, LSD 7.93). The susceptibility of $P$. plagipennis nymphs to indoxacarb, spinosad, fipronil and emamectin benzoate decreased as nymphs became more developed, with fourth and fifth instars remaining relatively unaffected by direct exposure (table 4).

\section{Field studies}

\section{2/03 Experiment}

Helicoverpa spp. and Creontiades spp. were abundant during the first experiment. Helicoverpa armigera (Hübner) was the dominant species, with only low numbers $(<20 \%)$ of Helicoverpa punctigera (Wallengren) observed. Green mirids, Creontiades dilutus (Stål) were the dominant species encountered during sampling, with only low numbers $(<10 \%)$ of brown mirids, Creontiades pallidifer (Walker), observed.

No significant $(P>0.05)$ differences in $P$. plagipennis nymph densities were recorded between the $P$. plagipennis alone and $P$. plagipennis with soft insecticide treatments during the experiment (fig. 1).

The conventional, soft insecticide only and soft insecticide and $P$. plagipennis treatments resulted in significantly $(P<0.001)$ reduced Creontiades spp. populations compared to the control (table 5). A significant reduction $(P<0.001)$ in Creontiades spp. numbers was also recorded in the $P$. plagipennis only treatment compared to the control during the latter half of January 2003 (table 5, fig. 2).

Significant reductions in looper, Chrysodeixis spp., densities were recorded in the conventional insecticide treatment

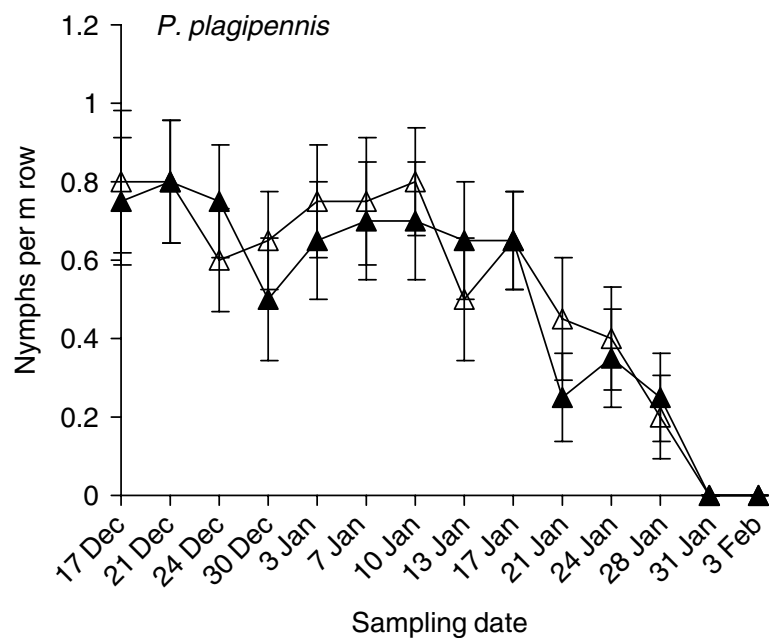

Fig. 1. Time series showing numbers per $\mathrm{m}$ row of Pristhesancus plagipennis nymphs sampled from all treatments for the 2002/03 experiment. The bars denote se. $-\mathbf{\Delta}-$, P. plagipennis, Only; $-\triangle-$, P. plagipennis \& Soft Insecticides.

$(P<0.01)$ compared to all other treatments (table 5). Significant $(P<0.01)$ reductions in looper densities were also recorded in both predator and soft insecticide only treatments compared with the untreated control (table 5).

Each of the treatments resulted in a significant reduction $(P<0.001)$ in large larvae densities compared to the untreated control with the conventionally sprayed and 
Table 5. The repeated measures analysis predicted treatment means for Creontiades spp., Chrysodexis spp. and large Helicoverpa larvae densities per metre crop row for the 2002/03 experiment duration.

\begin{tabular}{|c|c|c|c|c|c|c|}
\hline Treatment & \multicolumn{2}{|c|}{ Creontiades spp. } & \multicolumn{2}{|c|}{ Chrysodexis spp. } & \multicolumn{2}{|c|}{ Large Helicovpera larvae } \\
\hline Untreated control & 1.31 & $\mathrm{n} / \mathrm{a}$ & 1.78 & $\mathrm{n} / \mathrm{a}$ & 0.51 & $\mathrm{n} / \mathrm{a}$ \\
\hline Soft insecticides & 0.31 & 76.4 & 1.31 & 26.7 & 0.24 & 52.9 \\
\hline Soft insecticides and P. plagipennis & 0.30 & 77.0 & 1.28 & 27.7 & 0.15 & 70.5 \\
\hline Conventionally sprayed & 0.55 & 58.0 & 0.45 & 74.8 & 0.13 & 74.5 \\
\hline
\end{tabular}

The percentage pest reduction compared to the untreated control has been calculated and standard error of the differences and chi $P$ value is given.

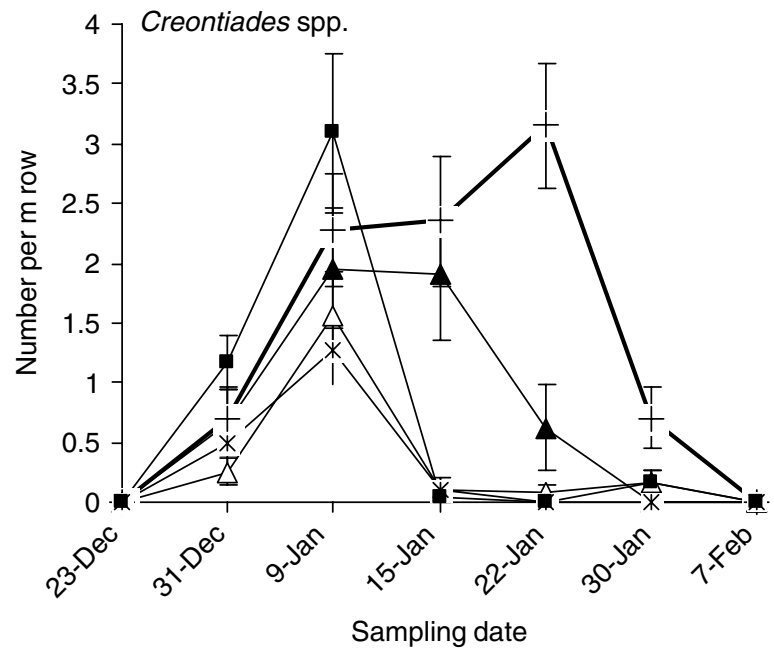

Fig. 2. Time series showing mean numbers per $\mathrm{m}$ row of Creontiades spp. sampled from all treatments for the 2002/03 experiment. The bars denote se. $-\mathbf{\Delta}-, P$. plagipennis Only; -+- , Untreated Control; $-\triangle-, P$. plagipennis \& Soft Insecticides; - - , Soft Insecticides Only; - - Conventionally Sprayed.

combined $P$. plagipennis/compatible insecticide treatments providing the largest reduction in larval densities compared to the control (table 5). The assessment of treatment effects on crop yield were hampered by extremely adverse wet weather conditions in February, which coincided with the onset of boll opening in the plots and caused extensive yield losses due to boll rots and tight loch $(>25 \%)$. The exception was the control treatment, where earlier insect damage had caused a later pattern of compensatory boll set. Despite the wet weather impacts, all treatments yielded significantly $(P<0.001)$ more lint than the control (table 6).

\section{3/04 Experiment}

No significant $(P>0.05)$ differences in $P$. plagipennis nymph densities were recorded between the $P$. plagipennis alone and $P$. plagipennis with soft insecticide treatments during the experiment (fig. 3).

The 2003/04 experiment was subject to very low levels of pest pressure with no Creontiades spp. and low numbers of
Table 6. Mean treatment lint yield (bales per hectare) for the 2002/03 and 2003/04 experiments.

\begin{tabular}{lcc}
\hline Treatment & \multicolumn{2}{c}{ Lint yield (bales ha ${ }^{-1}$ ) } \\
\cline { 2 - 3 } & $\begin{array}{c}2002 / 03 \\
\text { Experiment }\end{array}$ & $\begin{array}{c}2003 / 04 \\
\text { Experiment }\end{array}$ \\
\hline Untreated control & $5.3 \mathrm{a}$ & $9.34 \mathrm{a}$ \\
Pristhesancus plagipennis only & $6.73 \mathrm{~b}$ & $9.86 \mathrm{ab}$ \\
Soft insecticides & $6.91 \mathrm{~b}$ & $9.95 \mathrm{ab}$ \\
Soft insecticides and P. plagipennis & $6.94 \mathrm{~b}$ & $10.90 \mathrm{~b}$ \\
Conventionally sprayed & $7.22 \mathrm{~b}$ & $10.56 \mathrm{~b}$ \\
LSD at 5\% & 0.67 & 1.05 \\
\hline
\end{tabular}

Treatment means marked with different letters are significantly different $(P<0.05)$.

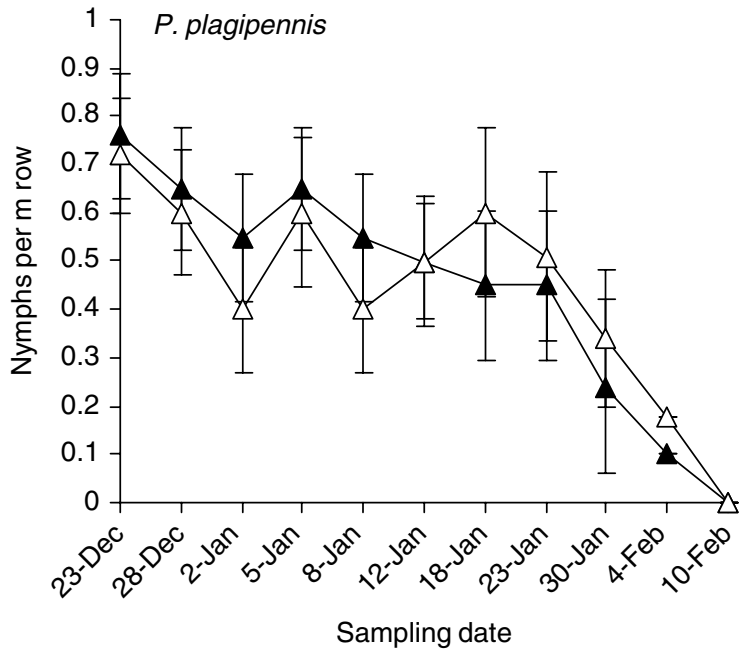

Fig. 3. Time series showing numbers per $\mathrm{m}$ row of Pristhesancus plagipennis nymphs sampled from all treatments for the 2003/04 experiment. The bars denote se. $-\mathbf{\Delta}-, P$. plagipennis Only; $-\triangle-$, P. plagipennis \& Soft Insecticides.

Helicoverpa spp. larvae recorded, of which $H$. punctigera was more prevalent (>60\%). Significantly lower densities $(P<0.001)$ of Helicoverpa spp. larvae were recorded in all of the predator and insecticide treatments compared to the control (table 7, fig. 4). A comparison of late instar larvae 
Table 7. The repeated measures analysis predicted treatment means for large and total Helicoverpa larvae densities per metre crop row for the 2003/04 experiment duration.

\begin{tabular}{lccccc}
\hline Treatment & \multicolumn{2}{c}{ Large Helicoverpa larvae } & & \multicolumn{2}{c}{ Total Helicoverpa larvae } \\
\cline { 2 - 3 } & Mean & \% Reduction nn & & Mean & \% Reduction \\
\hline Untreated control & 0.06 & $\mathrm{n} / \mathrm{a}$ & & 0.61 & $\mathrm{n} / \mathrm{a}$ \\
Pristhesancus plagipennis only & 0.01 & 83 & & 0.31 & 49.2 \\
Soft insecticides & 0.01 & 83 & & 0.36 & 41.0 \\
Soft insecticides and P. plagipennis & 0 & 100 & & 0.16 & 73.7 \\
Conventionally sprayed & 0 & 100 & & 0.21 & 65.5 \\
Standard error of differences & 0.01 & & & 0.06 & \\
Chi $P$ value & $<0.001$ & & & $<.001$ & \\
\hline
\end{tabular}

The percentage pest reduction compared to the untreated control has been calculated and standard error of the differences and chi $P$ value is given.

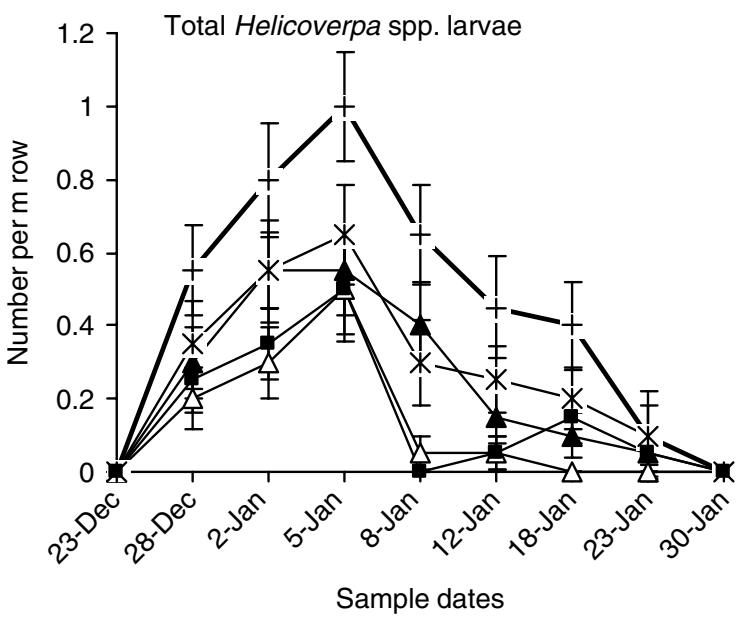

Fig. 4. Time series showing the mean numbers per $m$ row of all Helicoverpa spp. larval instars sampled from all treatments for the 2003/04 experiment. The bars denote se. - $\mathbf{\Delta -}, P$. plagipennis Only; - +-, Untreated Control; $-\triangle-$, P. plagipennis \& Soft Insecticides; - - , Soft Insecticides Only; - - , Conventionally Sprayed.

densities further suggested that both the $P$. plagipennis combined with soft insecticides and the conventionally sprayed treatments provided complete control with no large larvae recorded in the plots (table 7).

The conventional and P. plagipennis with soft insecticides treatments yielded the same amount of lint, both of which were significantly more $(P<0.05)$ than the unsprayed control (table 6).

\section{Discussion}

The tolerance of $P$. plagipennis to a range of new generation insecticides as shown by the laboratory insecticide compatibility studies is advantageous when considering its release into cotton production systems characterized by frequent insecticide use (Murray et al., 2005). Pristhesancus plagipennis tolerance to fipronil and indoxacarb provides compatible insecticides for the control of Creontiades spp. Previous registered options for Creontiades spp. control were predominantly organophosphate products, such as dimethoate and omethoate, which were found to be highly toxic to $P$. plagipennis during this and earlier experiments (Grundy et al., 2000a). The high toxicity of diafenthiuron to $P$. plagipennis was unexpected as previous research on related predators such as Nabis, Geocoris and Orius spp. that commonly occur in Australian cotton fields had suggested low toxicity (10-20\% mortality) to these predatory bug species (Deutscher et al., 2004). The high toxicity of imidacloprid to $P$. plagipennis also contradicted earlier research suggesting this nicotinoid was non-toxic to P. plagipennis (James \& Vogele, 2001), although this discrepancy appears to be due to differences in the application rates tested, with lower concentrations of active ingredient (a.i.) used in James \& Vogeles' experiment $(0.0053 \%$ vs. $0.5-0.125 \%$ a.i).

The increasing robustness of developing nymphs to insecticide exposure as observed for indoxacarb, spinosad, fipronil and emamectin benzoate indicated that products found to be moderately toxic on first instar nymphs could be used several weeks post-release in the field when nymphs have developed into older instars. The increased tolerance of $P$. plagipennis to insecticides with nymph development could allow for a broader range of insecticides to be used later in the season.

The field release experiments were conducted to test the use of $P$. plagipennis as a biological control agent within an integrated programme that aimed to reduce pesticide inputs whilst maintaining crop yield. The release of $P$. plagipennis combined with compatible insecticides provided equivalent pest insect reductions and crop yields compared to the conventional insecticide treatment, whilst reducing synthetic insecticide inputs (excluding nucleopolyhedrovirus biopesticides) by half. Significant reductions in pest densities were observed in the $P$. plagipennis only plots although the biological control recorded was characterized by a time lag of several days as was observed for Creontiades spp. (fig. 2). As anticipated from the laboratory studies, no deleterious effects of fipronil and indoxacarb applications on P. plagipennis densities were observed (fig. 1).

The impact $P$. plagipennis on Helicoverpa spp. and Creontiades spp. in the 2002/03 experiment was possibly diluted due to high densities of largely uneconomic Chrysodeixis spp. larvae that served as substitute prey as indicated by the significant reductions $(P<0.01)$ in this species recorded in the $P$. plagipennis treatments (table 5). In retrospect, the use of indoxacarb in place of Helicoverpa specific nucleopolyhedrovirus biopesticides during this experiment may have enhanced the subsequent levels of biological control afforded by $P$. plagipennis on Creontiades 
and Helicoverpa spp. by reducing the prevalence of Chrysodeixis spp. from the crop canopy.

The full potential of the treatments in terms of yield impacts were not fully realised in either experiment due to adverse wet weather and resultant boll loss in 2002/03 and very low pest densities in 2003/04 (the lint yield of the untreated control plots exceeded the best yields of the 2002/03 experiment). Despite these difficulties, it is notable that both experiments yielded equivalent quantities of lint from the $P$. plagipennis integrated with soft insecticides and the conventionally sprayed treatment plots, suggesting that an integrated biological control strategy could provide a comparable degree of economic control to a conventional insecticide dependant programme.

The present research, together with earlier studies (Grundy \& Maelzer, 2000; 2002; Grundy, 2004), suggests significant potential for the use of $P$. plagipennis as an inundative bio-control in cotton, although the adoption of this predator as part of an integrated strategy is doubtful at this stage. The Australian cotton industry has generally relied upon single technology solutions such as pesticide use (Fitt, 1994), and more recently transgenic Bt cotton varieties (Fitt, 2000) against which alternative pest management options such as applied biological controls are unlikely to compete on a cost versus efficacy basis alone. Such a challenge to the uptake of a biological control is not unique to $P$. plagipennis or the Australian cotton industry but prevalent throughout first world agricultural systems where pesticide control dominates (Waage, 1996).

The cost of rearing $P$. plagipennis nymphs in the laboratory has been estimated at AUD $\$ 3.52$ per 100 third instars (Grundy, 2001), which when released at the rates tested would equate to AUD\$352 per hectare excluding shipping and physical release costs. In comparison, the 2005 licence fee for Bollgard $\AA$ transgenic cotton varieties that provide near complete Helicoverpa spp. control was approximately AUD $\$ 300$ per hectare sown (Barber, 2005), which still leaves a considerable margin for secondary pest control compared to the cost of $P$. plagipennis release and use of compatible insecticides.

The primary expenses associated with rearing $P$. plagipennis were labour costs and the use of $T$. molitor as insect prey. Whilst considerable gains in labour efficiency could be expected with the commercial production of $P$. plagipennis, the use of T. molitor as a prey insect would remain expensive. The use of an artificial diet could circumvent the need for using host prey insects as has been demonstrated by Cohen (1985) who used beef and hens egg based diets for the rearing of Geocoris punctipes (Say) (Hemiptera: Lygaeidae) and later Chrysoperla carnea (Stephens) (Neuroptera: Chrysopidae) (Cohen \& Smith, 1998). These diets have since been demonstrated to have potential for rearing other predatory Heteroptera including various pentatomids (De Clercq \& Degheele, 1993; Zanuncio et al., 1996; De Clercq et al., 1998) and Dicyphus tamaninii (Wagner) (Heteroptera: Miridae) (Iriarte \& Castane, 2001). Basic experimentation with these described diets has suggested that $P$. plagipennis can also be reared from first instar nymphs to adults, although the fecundity of diet-reared insects was poor compared to those reared on T. molitor (P.R. Grundy, unpublished data, 2004). However, the acceptance and development of $P$. plagipennis on meat-based artificial diets suggests some potential to develop a suitable rearing substrate, which could significantly reduce the rearing costs for $P$. plagipennis and make it a more cost competitive pest control option for cotton.

Since $P$. plagipennis has a potential lifespan of 9-11 months (James, 1994), the adults can continue living well after a crop such as cotton has been destroyed. Therefore, an alternate strategy for increasing the value of inundative $P$. plagipennis releases in annual summer field crops is to try and retain a proportion of the released predator populations on-farm between summer seasons (thus reducing predator release requirements each season) through the provision of specifically planted vegetative refuge habitats to provide prey and shelter during the normally fallow winter months. However, experiments examining the potential for such a strategy did not identify any vegetative refuge types suitable for retaining $P$. plagipennis for the period of six months or more between summer cotton crops (Grundy \& Maelzer, 2003).

Without substantial advances in predator mass-rearing technologies, the cost of utilising inundatively released biocontrol agents, such as $P$. plagipennis, compared with increasingly sophisticated transgenic technologies is likely to prevent the uptake of this predator in cotton for the foreseeable future. Given the potential efficacy of $P$. plagipennis against larvae and bug pests, this bio-control may be better directed towards higher value crops such as citrus and berry fruits, where it has already been recorded as a potential mortality agent of bug pests (James, 1994; Coombs \& Khan, 1998). Within such perennial systems, a lower cost inoculative rather than inundative release strategy might be effective for increasing predator numbers to gain effective biological control. The integrated pest management programmes utilized by these industries are already partially reliant on inoculative releases of various other beneficial insect species (Smith et al., 1997) and may be more conducive to the uptake of a predator such as P. plagipennis.

\section{Acknowledgements}

The author would sincerely like to thank Geoff Morris and Alex Mathieson of the Queensland Department of Primary Industries and Fisheries (QDPI\&F) for maintaining the trial site used for this research. Sherree Short, David Lincoln and Nicole Purvis-Smith assisted with predator release and trial assessments. The author also thanks Christina Playford (QDPI\&F) for statistical advice. This research was financially supported by the Australian Cotton Research and Development Corporation (Project DAQ122C).

\section{References}

Abbott, W.S. (1925) A method for computing the effectiveness of an insecticide. Journal of Economic Entomology 18, 265-267.

Barber, J. (2005) New benchmarks and new opportunities. Australian Cotton Grower 26 (7) 59-62.

Cohen, A.C. (1985) Simple method for rearing the insect predator Geocoris punctipes (Heteroptera: Lygaeidae) on a meat diet. Journal of Economic Entomology 78, 1173-1175.

Cohen, A.C. \& Smith, L.K. (1998) A new concept in artificial diets for Chrysoperla carnea: the efficacy of solid diets. Biological Control 13, 49-54.

Coombs, M. \& Khan, S.A. (1998) Population levels and natural enemies of Plautia affinis (Dallas) (Hemiptera: Pentatomidae) on raspberry, Rubus idaeus L., in 
south-eastern Queensland. Australian Journal of Entomology 37, 125-129.

De Clercq, P. \& Degheele, D. (1993) Quality assessment of the predatory bugs Podisus maculiventris (Say) and Podisus sagitta (Fab.) (Heteroptera: Pentatomidae) after prolonged rearing on meat based artificial diet. Biocontrol Science and Technology 3, 133-139.

De Clercq, P., Merlevede, F. \& Tirry, L. (1998) Unnatural prey and artificial diets for rearing Podisus maculiventris (Heteroptera: Pentatomidae). Biological Control 12, 137-142.

Deutscher, S.A., Wilson, L.J. \& Mensah, R.K. (Eds) (2004) Integrated pest management guidelines for cotton production systems in Australia. The Australian Cotton Cooperative Research Centre, Narrabri, New South Wales.

Doyle, B., Reeve, I. \& Barclay, E. (2002) The performance of Ingard $\mathbb{R}$ cotton in Australia during the 2000-2001 season. Cotton Research and Development Corporation, Narrabri, New South Wales.

Farrer, R.R. \& Bradley, J.R. (1985) Within-plant distribution of Heliothis spp. (Lepidoptera: Noctuidae) eggs and larvae on cotton in North Carolina. Environmental Entomology 14, 205-209.

Fitt, G.P. (1994) Cotton pest management. Part 3. An Australian perspective. Annual Review of Entomology 39, 543-562.

Fitt, G.P. (2000) An Australian approach to IPM in cotton: integrating new technologies to minimise insecticide dependence. Crop Protection 19, 793-800.

Grundy, P.R. (2001) The augmentation of Pristhesancus plagipennis as a biological control agent of Helicoverpa spp., Creontiades dilutus and Nezara viridula in summer oil seed crops. PhD Thesis. School of Agriculture and Horticulture, University of Queensland, Australia.

Grundy, P.R. (2004) Impact of low release rates of the assassin bug Pristhesancus plagipennis (Walker) (Hemiptera: Reduviidae) on Helicoverpa spp. (Lepidoptera: Noctuidae) and Creontiades spp. (Hemiptera: Miridae) in cotton. Australian Journal of Entomology 43, 77-82.

Grundy, P. \& Maelzer, D. (2000) Assessment of Pristhesancus plagipennis (Walker) (Hemiptera: Reduviidae) as an augmented biological control in cotton and soybean crops. Australian Journal of Entomology 39, 305-309.

Grundy, P.R. \& Maelzer, D.A. (2002) Augmentation of the assassin bug Pristhesancus plagipennis Walker (Hemiptera: Reduviidae) as a biological control agent for Helicoverpa spp. in cotton. Australian Journal of Entomology 41, 192-196.

Grundy, P.R. \& Maelzer, D.A. (2003) Towards the on-farm conservation of the assassin bug Pristhesancus plagipennis (Walker) (Hemiptera: Reduviidae) during winter using crop plants as refuges. Australian Journal of Entomology 42, 153-158.

Grundy, P.R., Maelzer, D.A., Collins, P.J. \& Hassan, E. (2000a) Potential for integrating eleven agricultural insecticides with the predatory bug Pristhesancus plagipennis (Hemiptera: Reduviidae). Journal of Economic Entomology 93, 584-589.

Grundy, P.R., Maelzer, D.A., Bruce, A. \& Hassan, E. (2000b) A mass-rearing method for the assassin bug Pristhesancus plagipennis (Hemiptera: Reduviidae). Biological Control 18, 243-250.

Grundy, P.R., Sequiera, R. \& Short, S. (2004) Suitability of legume species as trap crops for management of Helicoverpa spp. (Lepidoptera: Noctuidae) in central Queensland cotton cropping systems. Bulletin of Entomological Research 94, 481-486.
Hassan, S.A., Bigler, F., Bogenschutz, H., Boller, E., Brun, J., Calis, J.N.M., Coremans-Pelseneer, J., Duso, C., Grove, A., Heimback, U., Helyer, N., Hokkanen, H., Lewis, G.B., Mansour, F., Moreth, L., Polgar, L., Samsoe-Petersen, L., Sauphanor, B., Staubli, A., Sterk, G., Vainio, A., van de Veire, M., Viggiani, G. \& Vogt, H. (1994) Results of the sixth joint pesticide testing programme of the IOBC/WPRSworking group (Pesticides and Beneficial Organisms). Entomophaga 39, 107-119.

Herron, G.A., Beattie, G.A.C., Kallianpur, A. \& Barchia, L. (1998) Influence of spray volume and oil concentration on the efficacy of petroleum spray oil against Myzus persicae (Sulzer) (Hemiptera: Aphididae) Australian Journal of Entomology 37, 70-73.

Holland, J.M. \& Chapman, R.B. (1995) Comparative toxic and sublethal effects of fluvalinate on the two spotted spider mite and European red mite. Experimental Applied Acarology 19, 549-570.

Holloway, J. \& Forrester, N.W. (1998) New insecticide chemistry for Australian cotton. Proceedings of the Ninth Australian Cotton Conference pp. 603-610. Broadbeach, Queensland. 12-14 August 1998, Australian Cotton Growers Research Association, Wee Waa, Australia.

Hoque, Z., Dillon, M., Farquharson, B. \& Kauter, G. (2000) Soft options can reduce costs and increase cotton profits. Australian Cotton Grower 21, 33-37.

Iriarte, J. \& Castane, C. (2001) Artificial rearing of Dicyphus tamaninii (Heteroptera: Miridae) on a meat based diet. Biological Control 22, 98-102.

James, D.G. (1994) Prey consumption by Pristhesancus plagipennis Walker (Hemiptera: Reduviidae) during development. Australian Entomologist 21, 43-47.

James, D.G. \& Vogele, B. (2001) The effect of imidacloprid on survival of some beneficial arthropods. Plant Protection Quarterly 16, 58-62.

Johnson, A. \& Farrell, T. (Eds) (2003) Cotton pest management guide 2003/2004. New South Wales Agriculture Department, Orange, Australia.

Johnson, M.L., Pearce, S., Wade, M., Davies, A., Silberbauer, 1., Gregg, P. \& Zalucki, M. (2000) Review of beneficials in cotton farming systems. Cotton Research and Development Corporation, Narrabri, New South Wales.

King, E.G. \& Powell, J. (1992) Propagation and release of natural enemies for control of cotton insect and mite pests in the United States. Crop Protection 11, 497-506.

Mansfield, S., Dillon, M.L. \& Whitehouse, M.E.A. (2006) Are arthropod communities in cotton really disrupted? An assessment of insecticide regimes and evaluation of the beneficial disruption index. Agriculture, Ecosystems and Environment 113, 326-335.

Mensah, R.K. (2002) Development of an integrated pest management programme for cotton. Part 1: establishing and utilizing natural enemies. International Journal of Pest Management 48 (2), 87-94.

Mensah, R.K., Liang, W., Gibb, D., Coates, R. \& Johnson, D. (2005) Improving the efficacy of nuclear polyhedrosis virus and Bacillis thuringiensis against Helicoverpa spp. with ultraviolet light protected petroleum spray oils on cotton crops in Australia. International Journal of Pest Management 51 (2), 101-109.

Miles, M.M. (1995) Identification, pest status, ecology and management of the green mirid, Creontiades dilutus (Stål) (Hemiptera: Miridae), a pest of cotton in Australia. PhD thesis. 
Department of Entomology, University of Queensland, St Lucia, Australia.

Murdoch, W.W., Chesson, J. \& Chesson, P.L. (1985) Biological control in theory and practice. American Naturalist 125, 344366.

Murray, D.A.H., Lloyd, R.J. \& Hopkinson, J.E. (2005) Efficacy of new insecticides for management of Helicoverpa spp. (Lepidoptera: Noctuidae) in Australian grain crops. Australian Journal of Entomology 44, 62-67.

New, T.R. (2002) Insects and pest management in Australian agriculture. 346 pp. Melbourne, Oxford University Press.

Nyffeler, M., Sterling, W.L. \& Dean, D.A. (1992) Impact of the striped lynx spider (Aranea: Oxyopidae) and other natural enemies on the cotton fleahopper (Hemiptera: Miridae) in Texas cotton. Biological Control 21, 1178-1188.

Payne, R., Lane, P.W., Ainsley, A.E., Bicknell, K,E., Digby, P.G.N., Harding, S.A., Leech, P.R., Simpson, R., Todd, A.D., Verrier, P.J. \& White, R.P. (1989) Genstat 5 Reference Manual. Oxford, Clarendon Press.

Pyke, B.A. \& Brown, E.H. (1996) The cotton pest and beneficial guide. 51 pp. Woolloongabba, Australia, GoPrint.

Schulze, K.J. \& Tomkins, A.R. (Eds) (2002) Cotton pest management guide 2002/2003. New South Wales Agriculture Department, Orange, Australia.

Sequeira, R. (2001) Inter-seasonal population dynamics and cultural management of Helicoverpa spp. in a central Queensland cropping system. Australian Journal of Experimental Agriculture 41, 249-259.

Smith, D., Beattie, G.A.C. \& Broadley, R. (Eds) (1997) Citrus pests and their natural enemies. 272 pp. Department of Primary Industries, Brisbane, Australia.
Stanley, J. (1997) The seasonal abundance and impact of predatory arthropods on Helicoverpa spp. in Australian cotton fields. PhD thesis. University of New England, Armidale, New South Wales, Australia.

Waage, J. (1996) 'Yes, but does it work in the field?' The challenge of technology transfer in biological control. Entomophaga 41, 315-332.

Wilson, L.J., Bauer, L.R. \& Lally, D.A. (1998) Effect of early season insecticide use on predators and outbreaks of spider mites (Acari: Tetranychidae) in cotton. Bulletin of Entomological Research 88, 477-488.

Wilson, L., Hickman, M. \& Deutscher, S. (2006) Research update on IPM and secondary pests. Proceedings of the Thirteenth Australian Cotton Conference. Gold Coast Queensland. 8-10 August 2006, Australian Cotton Growers Research Association, Wee Waa, Australia.

Zalucki, M.P., Daglish, G., Firempong, S. \& Twine, P. (1986) The biology and ecology of Heliothis armigera (Hübner) and $H$. punctigera (Wallengren) (Lepidoptera: Noctuidae) in Australia: what do we know? Australian Journal of Zoology 34, 779-814.

Zanuncio, J.C., Saavedra, J.L.D., Oliveira, H.N., De Clercq, P. \& Degheele, D. (1996) Development of the predatory stinkbug Brontocoris tabidus (Signoret) (Heteroptera: Pentatomidae) on different proportions of artificial diet and pupae of Tenebrio molitor L. (Coleoptera: Tenebrionidae). Biocontrol Science and Technology 6, 619-625.

(Accepted 13 November 2006)

(C) 2007 Cambridge University Press 